\title{
Frequencies of Functional Polymorphisms in Three Pharmacokinetic Genes of Clinical Interest within the Admixed Puerto Rican Population
}

\author{
Carmelo Orengo-Mercado ${ }^{1 *}$, Bianca Nieves ${ }^{2}$, Lizbeth López ${ }^{2}$, Nabila Vallés-Ortiz ${ }^{3}$, Jessicca Y. Renta ${ }^{1}$, Pedro J. Santiago-Borrero ${ }^{4}$, Carmen L. \\ Cadilla $^{1}$ and Jorge Duconge ${ }^{5}$ \\ ${ }^{1}$ Department of Biochemistry, School of Medicine, University of Puerto Rico, San Juan, Puerto Rico, USA \\ ${ }^{2}$ Faculty of Natural Sciences, Rio Piedras Campus, University of Puerto Rico, San Juan, Puerto Rico, USA \\ ${ }^{3}$ School of Natural Sciences, Bayamón Campus, University of Puerto Rico, Bayamón, Puerto Rico, USA \\ ${ }^{4}$ Puerto Rico Newborn Screening Program, Department of Pediatrics, School of Medicine, University of Puerto Rico, San Juan, Puerto Rico, USA \\ ${ }^{5}$ School of Pharmacy, Department of Pharmaceutical Sciences, University of Puerto Rico, San Juan, Puerto Rico, USA
}

\begin{abstract}
Objective: This cross-sectional study was aimed at determining the allele frequencies for the CYP2C19*2, CYP2C19*3, CYP2D6*10 and PON1 (rs662) polymorphisms in the Puerto Rican population. The CYP2C19, CYP2D6 and $P O N 1$ genes are known to be associated with functional changes in drug metabolism and activation. Individuals carrying the aforementioned polymorphisms are at a higher risk of suffering from drug-induced adverse events and/ or unresponsiveness from a variety of drugs that includes antidepressants, atypical antipsychotics and antiplatelet compounds. Information on the frequency of these polymorphisms is more commonly found on homogeneous populations, but is scarce in highly heterogeneous populations like Hispanics, as in the case of Puerto Ricans.
\end{abstract}

Method: Genotyping was carried out in 100 genomic DNA samples from dried blood spots supplied by the Puerto Rican Newborn Screening program using Taqman ${ }^{\circledR}$ Genotyping Assays.

Results: The Minor Allele Frequencies (MAF) obtained were $9 \%$ for CYP2C19*2 and CYP2D6 $10,50 \%$ for PON1 (rs662), while the CYP2C19*3 variant was not detected in our study. Furthermore, Hardy Weinberg equilibrium analysis was assessed as well as a comparison between Puerto Rico and other reference populations using a Z-test for proportions.

Conclusion: The observed allele and genotype frequencies on these relevant pharmacogenes in Puerto Ricans were more closely related to those early reported in two other reference populations of Americans (Mexicans and Colombians).

Keywords: CYP2C19; CYP2D6; PON1; Prevalence; Genotyping; Pharmacogenetics; Personalized medicine; Taqman ${ }^{\oplus}$; Guthrie filter cards

\section{Introduction}

The CYP2C19, CYP2D6 and PON1 genes encode for three different drug-metabolizing enzymes of clinical interest, which represents the major metabolic pathway for a variety of prescription drugs [1-3]. Individuals who carry one or two loss of function alleles in the CYP2C19, CYP2D6 and PON1 loci are at increased risk for drug-induced adverse events (e.g., antidepressants and atypical antipsychotics) and/or unresponsiveness (e.g., pro-drugs such as clopidogrel and tamoxifen) [1,4-13]. Accordingly, it is becoming increasingly clear that many patients will benefit from previous knowledge of their individual genotypes before initiating a therapy with such drug products. This assessment provides an opportunity to improve health standards in the medically underserved population of Puerto Rico to areas of medical need with potential disparities of care, notably including cancer, cardiovascular disease and mental illness. In addition, genotyping information of polymorphisms of pharmacogenetic value are a great resource for translational clinical science in global populations to develop personalized healthcare algorithms. Strikingly, such information is not yet fully available for Puerto Ricans.

The highly admixed structure and trichotomous ancestry of Puerto Ricans was early described by our group, after analyzing data from an array of 384 SNPs in 222 cardiometabolic and neuroendocrine genes $[14,15]$. The analysis revealed that each subject in the Puerto Rican population was a 'genetic mosaic', with contributions from each of these three clusters (i.e., Caucasians, Africans and Amerindians), but in widely different proportions. This admixture pattern gives rise to many combinatorial genotypes that impacts important pharmacological, biochemical and physiological pathways. Since such a rich repertoire of combinatorial genotypes is not present in traditional studies with more homogenous populations, we strongly believe that admixed populations (e.g., Hispanic Puerto Ricans) have the potential to be a better resource to develop DNA-guided algorithms for the treatment of different medical conditions $[14,15]$.

This cross-sectional study was aimed at determining prevalence of major CYP2C19, CYP2D6 and PON1 allelic variants in genomic DNA samples derived from Puerto Rican newborns. Comprehensive genotyping of these functional polymorphisms in pharmacokinetic genes of interest has not yet been examined in the admixed Puerto Ricans. We also ascertained how they compare to other reference parental populations, given the heterogeneous ethno-geographic

${ }^{*}$ Corresponding author: Carmelo Orengo-Mercado, Lab A639, 6 ${ }^{\text {th }}$ floor (Main Building), Department of Biochemistry School of Medicine, Medical Sciences Campus, University of Puerto Rico, P.O. Box 365067, San Juan, PR 00936-5067, Puerto Rico, USA, Tel: (787) 758 2525; Fax: (787)764-8209; E-mail: carmelo.orengo@upr.edu

Received February 18, 2013; Accepted March 22, 2013; Published March 27, 2013

Citation: Orengo-Mercado C, Nieves B, López L, Vallés-Ortiz N, Renta JY, et al. (2013) Frequencies of Functional Polymorphisms in Three Pharmacokinetic Genes of Clinical Interest within the Admixed Puerto Rican Population. J Pharmacogenom Pharmacoproteomics 4: 113. doi:10.4172/2153-0645.1000113

Copyright: (C) 2013 Orengo-Mercado C, et al. This is an open-access article distributed under the terms of the Creative Commons Attribution License, which permits unrestricted use, distribution, and reproduction in any medium, provided the original author and source are credited. 
Citation: Orengo-Mercado C, Nieves B, López L, Vallés-Ortiz N, Renta JY, et al. (2013) Frequencies of Functional Polymorphisms in Three Pharmacokinetic Genes of Clinical Interest within the Admixed Puerto Rican Population. J Pharmacogenom Pharmacoproteomics 4: 113. doi:10.4172/2153-0645.1000113

Page 2 of 6

heritage of Puerto Ricans. The study generated valuable data from the genetic background of Puerto Ricans by identifying and characterizing the allele and genotype frequency distributions for these clinically relevant polymorphisms in genes encoding drug-metabolizing enzymes, which provided substantial knowledge about expected interindividual variability in response to some anti-cancer, antidepressant and cardiovascular drugs.

\section{Materials and Methods}

100 genomic DNA were extracted and purified from dried-blood spotted on "Guthrie" filter cards, by using the GENTRA Generation DNA Purification Kit (QIAGEN Inc., Valencia, CA). DNA was quantified in the Nano Drop Spectrophotometer. Working DNA stock samples were stored at $-20^{\circ} \mathrm{C}$.

\section{Genotyping assay}

Genotyping of two major allelic variants (i.e., rs4244285 \& rs4986893) on the CYP2C19 locus, one major variant (i.e., rs1065852) on the CYP2D6 locus and the PON1 rs662, also known as the Q192R variant allele, were carried out on peripheral leukocyte DNAs by using Taqman-based SNP genotyping assay (Applied Biosystem). DNA amount ranged from 14 to $20 \mathrm{ng}$. The real time PCR reactions took place in 96 or 48-well plates run in the Applied Biosystems Step One Plus Real Time PCR system. Cycling parameters were: 30 seconds at $60^{\circ} \mathrm{C}, 10$ minutes at $95^{\circ} \mathrm{C}, 50$ cycles of 15 seconds at $92^{\circ} \mathrm{C}$ and 1 minute at $60^{\circ} \mathrm{C}$, and a final step of 30 seconds at $60^{\circ} \mathrm{C}$.

\section{Statistical analyses}

The 95\% Confidence Intervals (CI) for allele and genotype frequencies were calculated according to the method of Newcombe and Altman [16]. Data were used for comparing the frequency distributions of observed genotypes in our study cohort to the frequencies published in available databases for various non-Hispanic populations [17] using z-test for independent proportions. Departure from Hardy-Weinberg equilibrium (HWE) was tested under the null hypothesis of the predictable segregation ratio of specific matching genotypes $(p>0.05)$ by use of the $\chi^{2}$ goodness-of-fit test or alternatively a binomial test if frequencies are lower than $5 \%$.

\section{Results}

This research represents a non-interventional, cross-sectional, pharmacogenetic study of genomic DNA samples provided by the Puerto Rico Newborn Screening Program (PRNSP) in order to determine the frequency distribution of selected polymorphisms, namely, PON1 (rs662), CYP2D6 $6^{\star} 10, C Y P 2 C 19^{*} 2$ and CYP2C19*3 in the Puerto Rican newborn population (Table 1 for SNP's information). The collected samples, which were provided as dried blood spotted on filter (Guthrie) cards are representative of the different geographic regions of the Island of Puerto Rico. Indeed, these samples were selected from all Puerto Rico hospitals with birthing facilities following a controlled, stratified-by-region, random sampling procedure that took into consideration the regional birthrates of the Commonwealth of Puerto Rico, as documented on the 2004 National Birth Registry. The samples were analyzed using the Taqman ${ }^{\circ}$ genotyping assays. This type of sample has been successfully used previously for SNP genotyping with Taqman ${ }^{\circ}$ genotyping assays [16]. Although 100 unrelated specimens were initially selected for conducting the study, the CYP2C19*2 was evaluated in 99 samples, CYP2C19*3 in 96 samples and PON1 SNP was evaluated in 99 samples. One hundred genotyping results are reported for $C Y P 2 D 6^{\star} 10$.

\section{CYP2C19 locus}

The minor allele frequency (MAF) of $C Y P 2 C 19^{\star} 2$ was $9 \%$ (Figure 2). No significant deviation from Hardy-Weinberg equilibrium was found, according to the goodness-of-fit $\chi^{2}$-test $\left(\chi^{2}=0.12, p>0.05\right)$. The genotyping results for the CYP2C19*2 allele showed that 83 out of 99 genomic DNA samples tested $(84 \%)$ were found to be $\mathrm{G} / \mathrm{G}$ and, therefore, homozygous for the wild-type allele; another 15 DNA samples (15\%) were single carrier for the allelic variant ${ }^{\star} 2$ (i.e., $A / G$, heterozygous); whereas, only one DNA sample (1\%) was homozygous (A/A) for this clinically relevant polymorphism (Figure 1).

We compared this result with other populations (i.e., data taken from the Hap Map project and 1000 Genomes Phase I project for the America population) [17]) and found that the calculated frequency of carriers in the target population was lower than that in the reference populations. The East Asian population showed the higher frequency (i.e., 27\%), and was found to be significantly different from the Puerto Rican population ( $p<0.001, Z$-score: 4.85$)$ (Figure 2$)$. The African, European and American population presents a frequency of $14 \%$, while the Puerto Rican samples from the 1000 Genomes project showed an allele frequency of $13 \%$ [17].

\section{PON1 Locus}

The PON1 (rs662) polymorphism was found to be very frequent in our samples with a surprisingly $50 \%$ of carriers for the variant allele (Figure 1). The genotype results for rs662 in the analyzed samples was 22 were $\mathrm{C} / \mathrm{C}$ (homozygous for the common allele), $55 \mathrm{C} / \mathrm{T}$ (heterozygous) and $22 \mathrm{~T} / \mathrm{T}$ (homozygous for the variant allele) as shown in figure 1. The $\mathrm{T} / \mathrm{T}$ homozygous individuals were associated with lower plasma clopidogrel concentration and lower platelet inhibition in Caucasian [1]. When compared to other populations, the minor allele frequency (T) in Puerto Ricans was among the highest with $50 \%$, second to European with $71 \%$. Next, with lower minor allele frequencies are the East Asia population with a $36 \%$, and the African population with $28 \%$ (Figure 2). The allele frequency distribution of the PON1 rs662 polymorphism in this study cohort was found to meet Hardy Weinberg equilibrium $\left(\chi^{2}=1.22, \mathrm{p}>0.05\right.$, Figure 1$)$. The observed prevalence for this variant is consistent with reports in 126 Latin America inhabitants (Mexicans and Colombians; 1,000 Genomes Phase I selection) and 58 Mexican descendants who reside in Los Angeles, California (HapMapMEX; HapMap project dataset, release\#28, Phase II+III), where the PON1 minor allele frequencies were estimated to be $47 \%$ and $50 \%$, respectively, as well as the 55 Puerto Rican samples in the 1000 Genomes project (48\%) [17].

\section{CYP2D6 Locus}

Our findings in CYP2D6 $6^{\star} 10$ polymorphism $(100 \mathrm{C}>\mathrm{T}$ missense, rs1065852, Pro34Ser) in Puerto Ricans suggested that the variant rs1065852 (T) allele is rare among Puerto Rican newborns, with an estimated MAF of $9 \%$ (Figure 2). No significant departure from HWE was found $(\chi 2=2.11, p>0.05)$. The genotyping results for this

\begin{tabular}{|c|c|c|c|}
\hline Gene & SNP & $\begin{array}{c}\text { DNA } \\
\text { Change }\end{array}$ & $\begin{array}{c}\text { AA } \\
\text { Change }\end{array}$ \\
\hline CYP2C19*2 & rs4244285 & A/G & Splicing Defect \\
\hline CYP2C19*3 & $r s 4986893$ & A/G & Stop Codon \\
\hline PON1 & rs662 & C/T & Q $>$ R \\
\hline CYP2D6*10 & rs1065852 & C/T & P $>$ S \\
\hline
\end{tabular}

AA stands for amino acid.

Table 1: SNPs information 
Citation: Orengo-Mercado C, Nieves B, López L, Vallés-Ortiz N, Renta JY, et al. (2013) Frequencies of Functional Polymorphisms in Three Pharmacokinetic Genes of Clinical Interest within the Admixed Puerto Rican Population. J Pharmacogenom Pharmacoproteomics 4: 113. doi:10.4172/2153-0645.1000113

Page 3 of 6
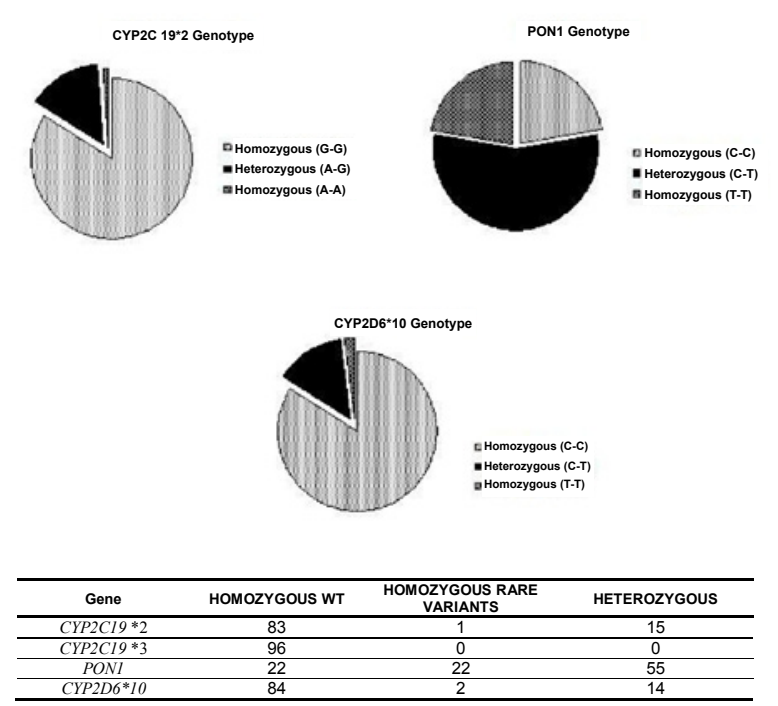

Figure 1: Pie charts illustrating the genotyping results (i.e., common homozygous, heterozygous, variant homozygous) for CYP2C19*2, PON1 Q192R (rs662), CYP2D6 10 polymorphisms in a sample representing the Puerto Rican population. A chart corresponding to CYP2C19*3 is not shown since we did not found the polymorphism in the samples analyzed.

SNP showed that $84 \%$ of genomic DNA samples tested were found to be homozygous for the wild-type allele (C/C); 14\% of DNA samples were heterozygous $(\mathrm{C} / \mathrm{T})$; whereas, only two DNA samples $(2 \%)$ were homozygous (T/T) for this SNP (Figure 1).

By comparing this result with those reported for other populations in the 1000 Genomes Phase 1 databases [17], we found that the calculated frequency of $\mathrm{T}$ carriers in Puerto Ricans (9\%) were lower than those obtained in the 55 samples submitted to the 1000 Genomes Project $(20 \%)$ and to those of other reference populations such as Europeans, East Asians and Americans. Significant differences were found between Puerto Ricans and either Europeans or East Asians, as determined by comparison for proportions using Z-tests $(p \leq 0.001$, $Z$-score: 3.22 ; and $p<0.001, Z$-score: 9.52, respectively, Figure 2). Indeed, both East Asian and European populations showed the highest frequencies of the $\mathrm{T}$ allele (i.e., $52 \%$ and $20 \%$, respectively), followed by Americans with $16 \%$. It is worth noticing that in the case of the East Asian population the non-ancestral allele $(\mathrm{T})$ is the more frequent. However, the minor allele frequency (MAF) for the $\mathrm{T}$ allele reported in the African population was $9 \%$, the same T allele frequency observed in our study population (Figure 2).

\section{Discussion}

We have performed the HWE test in order to ensure that the observed allele and genotypes proportions are in equilibrium in the study population (i.e., across generations). It is particularly important because DNA specimens in this survey were collected from Puerto Rican newborns and it might be erroneously assumed that the reported frequencies for polymorphisms on all the three loci are only valid for newborns. In doing so, we can provide statistical validity of these frequencies for the entire population of Puerto Rico, despite of being computed by data collected from newborns only.

\section{CYP2C19 locus}

Clopidogrel have demonstrated to be highly effective at preventing thrombosis in patients worldwide [18,19]. Accordingly, this anti-platelet drug was selected in 2002 as the preferred $\mathrm{P}_{2} \mathrm{Y}_{12}$ receptor antagonist by the American College of Cardiology and American Heart Association (ACC/AHA), whose guidelines recommend it for the treatment of ACS or myocardial infarction with ST-segment elevation (STEMI) [1921]. Since a significant number of Puerto Rican patients qualify for clopidogrel therapy based on medical needs, the generic transition in 2012 (i.e., patent expired in May 2012) will increase eligible patients and, therefore, the amount of non-responders is expected to skyrocket. For this reason, we firmly believe that pharmacogenetic testing for functional CYP2C19 polymorphisms (e.g., CYP2C19*2; *3), and perhaps for the PON1 Q192R variant, has proven useful in identifying responders versus non-responders within the Puerto Rican population of patients undergoing PCI [1,2,5,6,19,22].

In a previous study [23], genotyping analyses using both a RFLPPCR method and a physiogenomic (PG)-array through Illumina BeadArray ${ }^{\mathrm{TM}}$ technology revealed a slightly higher $C Y P 2 C 19^{\star} 2$ minor allele frequency in Puerto Ricans of $14 \%$. In addition, the frequency of CYP2C19 2 carriers in the cohort of 99 Puerto Rican newborns tested in the current survey was $16 \%$ (i.e., $15 \%$ carriers and $1 \%$ homozygotes for the variant). Figure 1 contrasts with an earlier observed frequency of $26 \%$ of CYP2C19 2 carriers (i.e., $24 \%$ carriers and $1 \%$ homozygotes for the variant) in the same population [23]. However, the difference between these genotype frequencies were not statistically significant $(\mathrm{p}=0.09)$. It is known that the prevalence of CYP2C19 poor metabolizers (PM) in Caucasians and Africans ranges from 2 to $5 \%$, whereas it is $\sim 15 \%$ in Asians, and that the most common loss-of-function variant is the CYP2C19*2 polymorphism, which accounts for $75-83 \%$ of the defective alleles in PMs. CYP2C19*2 is inherited as an autosomal codominant trait; therefore, drug responsiveness in heterozygotes $\left({ }^{\star} 1{ }^{\star} 2\right)$ lies somewhere between the responsiveness in individuals with the ${ }^{*} 1 /{ }^{*} 1$ genotype and those with the ${ }^{*} 2 /{ }^{*} 2$ genotype. Accordingly, based on identified CYP2C19 genotypes, 83 individuals can be categorized as extensive metabolizers, 15 intermediate metabolizers (IM) (e.g., ${ }^{\star} 1 /{ }^{\star} 2$ ), and one poor metabolizer (e.g., ${ }^{\star} 2 /{ }^{\star} 2$ ). We think that the observed high degree of admixture in Puerto Ricans is responsible for the slightly lower frequency of PMs found in our study cohort as compared to Europeans (i.e., 1-2\% versus expected 2-5\%), although not significant difference in the frequency of $C Y P 2 C 19^{\star} 2$ were found between both populations $(p=0.15)$. If we take all three genes into account, our findings suggested that Puerto Ricans are more closely related to the American population (Mexican ancestry in Los Angeles, CA; Colombian in Medellin), which is also highly admixed, and secondly to Africans due probably to their strong influence on the genetic backgrounds of Puerto Ricans.

In contrast, the $\mathrm{CYP} 2 \mathrm{C} 19^{*} 3$ rare variant was not found in any of the 96 samples analyzed for this polymorphism (i.e., all the samples were of wild type genotype for this SNP). This is consistent with our previous report in this population [23], where we could not detect any carriers or individual homozygous for this rare polymorphism, confirming that the frequency for the CYP2C19*3 allele is lower than that for the CYP2C19*2 allele in the Puerto Rican population. The 1000 Genomes project Phase I reports the East Asian population with a 5\% minor allele frequency, nevertheless, the rare variant of $C Y P 2 C 19^{*} 3$ was not found in the rest of the populations tested, including the Puerto Rican samples. In this regard, we cannot rule out that other CYP2C19 rare variants (e.g., CYP2C19*4, ${ }^{\star} 8$, and ${ }^{\star} 17$ ) may be present, including unknown alleles with reduced or absent enzymatic activity. 
Citation: Orengo-Mercado C, Nieves B, López L, Vallés-Ortiz N, Renta JY, et al. (2013) Frequencies of Functional Polymorphisms in Three Pharmacokinetic Genes of Clinical Interest within the Admixed Puerto Rican Population. J Pharmacogenom Pharmacoproteomics 4: 113. doi:10.4172/2153-0645.1000113

\section{CYP2C19*2}

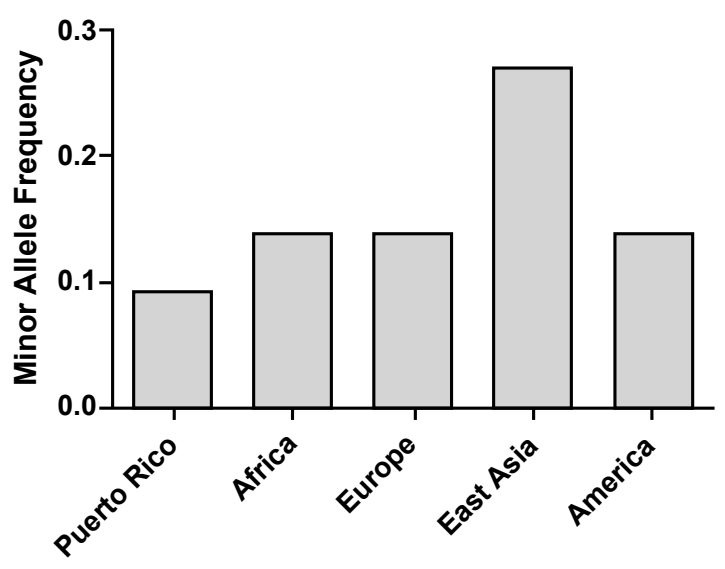

PON1

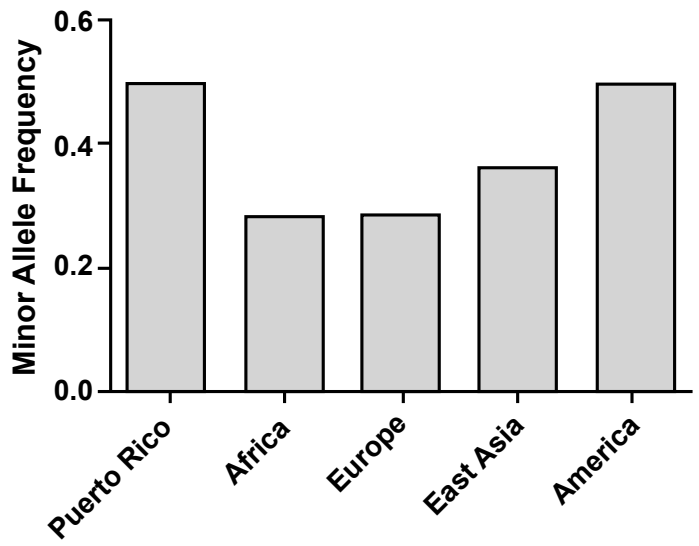

\section{CYP2D6*10}

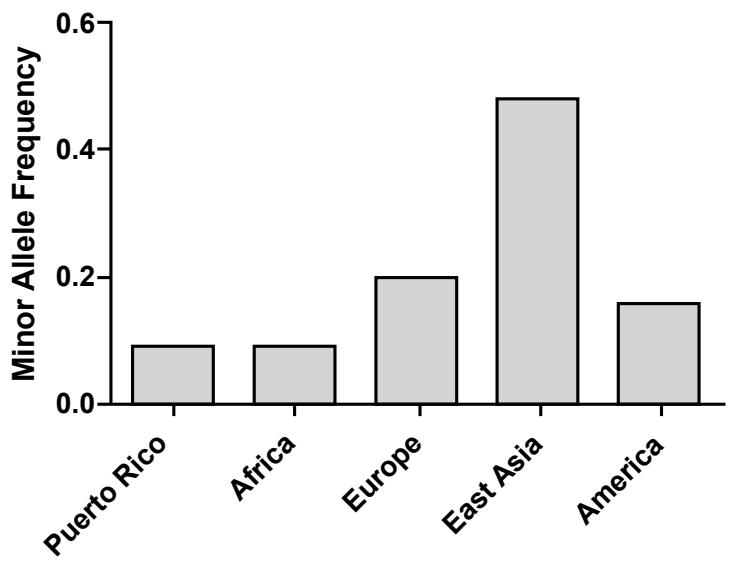

Minor Allele Frequency (MAF) and Population Comparison

\begin{tabular}{|c|c|c|c|c|c|c|c|c|c|}
\hline \multirow[b]{2}{*}{ Gene } & \multirow{2}{*}{$\begin{array}{l}\text { Puerto Rico } \\
\underline{\text { MAF }}\end{array}$} & \multicolumn{2}{|l|}{$\underline{\text { Africa }}$} & \multicolumn{2}{|l|}{ Europe } & \multicolumn{2}{|c|}{$\underline{\text { East Asia }}$} & \multicolumn{2}{|c|}{$\underline{\text { America }}$} \\
\hline & & $\underline{\text { MAF }}$ & p value & $\underline{\text { MAF }}$ & p value & $\underline{\text { MAF }}$ & p value & $\underline{\text { MAF }}$ & p value \\
\hline СYР 2 C $19 * 2$ & $0.09(\mathrm{~A})$ & $0.14(\mathrm{~A})$ & 0.154 & $0.14(\mathrm{~A})$ & 0.155 & $0.27(\mathrm{~A})$ & 0 & $0.14(\mathrm{~A})$ & 0.285 \\
\hline PONI & $0.50(\mathrm{~T})$ & $0.28(\mathrm{~T})$ & 0 & $0.29(\mathrm{C})$ & 0 & $0.36(\mathrm{~T})$ & 0.013 & $0.50(\mathrm{~T})$ & 1 \\
\hline$C Y P 2 D 6^{*} 10$ & $0.09(\mathrm{~A})$ & $0.09(\mathrm{~A})$ & 0.977 & $0.20(\mathrm{~A})$ & 0.001 & $0.48(\mathrm{G})$ & 0 & $0.16(\mathrm{~A})$ & 0.133 \\
\hline
\end{tabular}

rs4244285 and rs662 population data was retrieved from the Hap Map \#28 Project. African data is composed from individuals of African ancestry in Southwest USA; Luhya in Webuye, Kenya; Maasai in Kinyawa, Kenya; Yoruba in Ibadan, Nigeria. Europe: Utah residents with N \& W European ancestry from the CEPH collection; Toscans in Italy. East Asia: Han Chinese in Beijing, China; Chinese in Metropolitan Denver, Colorado; Japanese in Tokyo, Japan. America: Mexican ancestry in Los Angeles, California. rs4986893 and rs1065852 population data was retrieved from the 1000 Genomes Phase I Project: African data is composed from individuals of African ancestry in Southwest USA; Luhya in Webuye, Kenya; Yoruba in Ibadan, Nigeria. Europe: Utah residents with N \& W European ancestry from the CEPH collection; Finnish in Finland; British in England and Scotland; Iberian populations in Spain; Toscans in Italy. East Asia: Han Chinese in Beijing, China; Han Chinese South; Japanese in Tokyo, Japan. America: Colombian in Medellín, Colombia; Mexican ancestry in Los Angeles, California [17].

Figure 2: Minor Allele Frequency (MAF) corresponding to genetic polymorphisms on CYP2C19*2, PON1 and CYP2D6 loci in Puerto Ricans and 4 other reference populations. Comparison between Puerto Ricans and other reference populations using a Z-test for proportions is shown. $5 \%$ significance level was selected. A graph corresponding to CYP2C19*3 is not shown since we did not found the polymorphism in the samples analyzed. 
Citation: Orengo-Mercado C, Nieves B, López L, Vallés-Ortiz N, Renta JY, et al. (2013) Frequencies of Functional Polymorphisms in Three Pharmacokinetic Genes of Clinical Interest within the Admixed Puerto Rican Population. J Pharmacogenom Pharmacoproteomics 4: 113. doi:10.4172/2153-0645.1000113

Cytochrome P450 isoenzyme 2C19 (CYP2C19) is one of the principal hepatic enzymes involved in the bio-activation of the antiplatelet pro-drug clopidogrel (i.e., Plavix ${ }^{\infty}$ and generic versions), but also contributes to the metabolism of many clinically relevant drugs such as antidepressants, benzodiazepines, mephenytoin, and some proton pump inhibitors. Like many other CYP450 superfamily members, the CYP2C19 gene is highly polymorphic, having more than 25 known variant alleles ( http://www.cypalleles.ki.se/cyp2c19.htm). Patients who suffer from acute coronary syndromes (ACSs) and carry at least one of these two common loss-of-function SNPs, CYP2C19*2 (splicing defect, c.681G $>\mathrm{A} ;$ rs4244285) and CYP2C19*3 (stop codon, c.636G >A; rs 4986893), are at a higher risk of cardiovascular events after being treated with clopidogrel, especially in those with a percutaneous coronary intervention (PCI). This clopidogrel resistance has been reported to be present in $\sim 25-50 \%$ of the population $[4,18,24]$. Clopidogrel resistance is an emerging clinical entity with potentially severe consequences such as recurrent myocardial infarction (MI), stroke, or death.

\section{PON1 locus}

In a previous analysis using the PG-array through Illumina BeadArray ${ }^{\mathrm{TM}}$ technology, our group observed an overall allele frequency for this PON1 polymorphism in Puerto Ricans that was 45\% [25].

Clopidogrel resistance is multi-factorial, but this patient's reduced capacity to produce the necessary levels of active metabolite in order to block platelet activation has also been previously associated with genetic variants on the PON1 locus (accounts for $\sim 12 \%$ variability) $[1,2,5,6,25]$. The PON1 Q192R (rs662) polymorphism have been suggested to account for up to $72 \%$ of clopidogrel response variability in individuals of European ancestry $[1,25]$. However, no evidence of significant association between genetic variants in the PON1 locus and individual platelet response to clopidogrel was found in a group of related healthy subjects of Amish descent [5,25]. Unfortunately, the use of an already available, rapid and reliable genetic test for the identification of clopidogrel resistance in Hispanic Puerto Ricans is still pending [25].

\section{CYP2D6 locus}

CYP2D6 product is a key enzyme for the metabolism of about 20$25 \%$ of prescribed drugs, including antipsychotics, antidepressants (e.g., selective serotonin reuptake inhibitors), antiarrhythmic, analgesics, and anticancer drugs such as tamoxifen (Nolvadex'), an estrogen-receptor modulator that has been widely used for the treatment of patients with hormone-dependent breast cancer [8]. There is a large inter-subject and inter-ethnic variability in drugs metabolism through the CYP2D6 pathway, which can be explained largely by genetic polymorphisms affecting the enzyme's function and expression. Earlier reports suggest that the CYP2D6 $6^{\star} 10(100 \mathrm{C}>\mathrm{T}, r s 1065852)$ variant is associated with either an IM or PM status and, therefore, a higher risk of adverse effects or non-response to pro-drugs such as tamoxifen $[8,26]$. The PM phenotype is characterized by complete absence of CYP2D6 enzyme activity, a metabolic status that is found in approximately $7-10 \%$ of Caucasians but in less than $1 \%$ of Asians $[9,27,28]$. The CYP2D6 $6^{\star} 10$ is a major variant in Asians, and is associated with diminished CYP2D6 activity resulting from an unstable, partially functioning enzyme. Approximately $50 \%$ of East Asians carry this T allele [29,30]; whereas, in Caucasians it is carried by only $2 \%$ [30-32]. On the other hand, there have been some controversies in the interpretation of the association analyses of CYP2D6 genotypes and the efficacy of tamoxifen $[8,33,34]$. In a previous study, $C Y P 2 D 6^{\star} 10 /{ }^{\star} 10$ was found to be associated with significantly lower steady-state plasma concentrations of active tamoxifen metabolites (i.e., 4-hydroxy-N-desmethyltamoxifen, a.k.a. endoxifen, and 4-hydroxytamoxifen), and the authors reasoned that it could possibly influence the clinical outcome of tamoxifen treatment in Asian breast cancer patients [7]. They also claimed that CYP2D6*10/*10 was significantly more frequent among non-responders ( $100 \%$ vs. $50 \%$, $p=0.0186)$ and their CYP2D6 genotype status affected the time to progression.

The wild type (normal) base at this nucleotide position is C. The $\mathrm{T}$ variant indicates the presence of a non-wild type CYP2D6 variant, which also occurs in many different variants. The most common variant in which it appears in is $C Y P 2 D 6^{\star} 10$, where it is the defining SNP, as well as the CYP2D6 ${ }^{\star} 4$ haplotype (i.e., the most common variant among Caucasians). While it is not possible for this polymorphism to identify one particular haplotype, all the variants in which it appears have reduced or no CYP2D6 activity.

Accordingly, and based on identified CYP2D6 ${ }^{\star} 10$ genotypes in this survey, 84 individuals can be categorized as extensive metabolizers (i.e., C/C carriers), 14 as IMs (i.e., C/T), and two PMs (T/T). Again, we strongly believe that the substantial admixture degree among Puerto Ricans, and particularly in this case, the significant contribution of African ancestry to the current genetic pool of Puerto Ricans, is responsible for the relative lower frequency of the $\mathrm{T}$ allele found in our study cohort as compared to Europeans (i.e., 9\% versus expected 20\%).

\section{Acknowledgement}

This investigation was supported in part by a grant from the National Heart, Lung and Blood Institute (SC2HL110393). RCMI grants from the National Center for Research Resources (2G12-RR003051) and the National Institute on Minority Health and Health Disparities (8G12-MD007600) from the National Institutes of Health provided infrastructure support. This protocol was approved by the UPR MSC IRB (Protocol A4070107). We thank the Puerto Rico Newborn Screening Program (PRNSP) for kindly providing samples for this study. NCRR Grant P20RR16470, NIGMS Grants P20GM103475 and R25GM061838, which funds the UPR MSC MBRS-RISE Program, provided partial support. We wish to thank Ms. Marisarah Torres for her assistance in this survey.

\section{References}

1. Bouman HJ, Schömig E, van Werkum JW, Velder J, Hackeng CM, et al. (2011) Paraoxonase-1 is a major determinant of clopidogrel efficacy. Nat Med 17: 110116.

2. Mega JL, Simon T, Collet JP, Anderson JL, Antman EM, et al. (2010) Reducedfunction CYP2C19 genotype and risk of adverse clinical outcomes among patients treated with clopidogrel predominantly for PCl: a meta-analysis. JAMA 304: 1821-1830.

3. Kirchheiner J, Brøsen K, Dahl ML, Gram LF, Kasper S, et al. (2001) CYP2D6 and CYP2C19 genotype-based dose recommendations for antidepressants: a first step towards subpopulation-specific dosages. Acta Psychiatr Scand 104: 173-192.

4. Wang TH, Bhatt DL, Topol EJ (2006) Aspirin and clopidogrel resistance: an emerging clinical entity. Eur Heart J 27: 647-654.

5. Shuldiner AR, O'Connell JR, Bliden KP, Gandhi A, Ryan K, et al. (2009) Association of cytochrome P450 2C19 genotype with the antiplatelet effect and clinical efficacy of clopidogrel therapy. JAMA 302: 849-857.

6. Mega JL, Close SL, Wiviott SD, Shen L, Hockett RD, et al. (2009) Cytochrome p-450 polymorphisms and response to clopidogrel. N Engl J Med 360: 354-362.

7. Lim HS, Ju Lee H, Seok Lee K, Sook Lee E, Jang IJ, et al. (2007) Clinica 
Citation: Orengo-Mercado C, Nieves B, López L, Vallés-Ortiz N, Renta JY, et al. (2013) Frequencies of Functional Polymorphisms in Three Pharmacokinetic Genes of Clinical Interest within the Admixed Puerto Rican Population. J Pharmacogenom Pharmacoproteomics 4: 113. doi:10.4172/2153-0645.1000113

implications of CYP2D6 genotypes predictive of tamoxifen pharmacokinetics in metastatic breast cancer. J Clin Oncol 25: 3837-3845.

8. Goetz MP, Rae JM, Suman VJ, Safgren SL, Ames MM, et al. (2005) Pharmacogenetics of tamoxifen biotransformation is associated with clinical outcomes of efficacy and hot flashes. J Clin Oncol 23: 9312-9318.

9. Alván G, Bechtel P, Iselius L, Gundert-Remy U (1990) Hydroxylation polymorphisms of debrisoquine and mephenytoin in European populations. Eur J Clin Pharmacol 39: 533-537.

10. Bernard S, Neville KA, Nguyen AT, Flockhart DA (2006) Interethnic differences in genetic polymorphisms of CYP2D6 in the U.S. population: clinical implications. Oncologist 11: 126-135.

11. Jann MW, Cohen LJ (2000) The influence of ethnicity and antidepressant pharmacogenetics in the treatment of depression. Drug Metabol Drug Interact 16: 39-67.

12. Chou WH, Yan FX, de Leon J, Barnhill J, Rogers T, et al. (2000) Extension of a pilot study: impact from the cytochrome P450 2D6 polymorphism on outcome and costs associated with severe mental illness. J Clin Psychopharmacol 20: 246-251.

13. Bondy B, Spellmann I (2007) Pharmacogenetics of antipsychotics: useful for the clinician? Curr Opin Psychiatry 20: 126-130.

14. Ruaño G, Duconge J, Windemuth A, Cadilla CL, Kocherla M, et al. (2009) Physiogenomic analysis of the Puerto Rican population. Pharmacogenomics 10: $565-577$.

15. Duconge J, Ruaño G (2010) The Emerging Role of Admixture in the Pharmacogenetics of Puerto Rican Hispanics. J Pharmacogenomics Pharmacoproteomics 1.

16. Newcombe R, Altman D (2000) Calculating confidence intervals for proportions and their differences in Statistics with Confidence. British Medical Journal.

17. Amigo J, Salas A, Phillips C, Carracedo A (2008) SPSmart: adapting population based SNP genotype databases for fast and comprehensive web access. BMC Bioinformatics 9: 428.

18. Gurbel PA, Bliden KP, Hiatt BL, O'Connor CM (2003) Clopidogrel for coronary stenting: response variability, drug resistance, and the effect of pretreatment platelet reactivity. Circulation 107: 2908-2913.

19. Duconge J, Ruaño G (2012) 'Generic to genetic' transition in cardiovascular and neuropsychiatric drugs: opportunity for personalized medicine. Pharmacogenomics 13: 1097-1100.

20. Kushner FG, Hand M, Smith SC, King SB, Anderson JL, et al. (2009) 2009 Focused Updates: ACC/AHA Guidelines for the Management of Patients With ST-Elevation Myocardial Infarction (updating the 2004 Guideline and 2007 Focused Update) and ACC/AHA/SCAI Guidelines on Percutaneous Coronary Intervention (updating the 2005 Guideline and 2007 Focused Update): a report of the American College of Cardiology Foundation/American Heart Association Task Force on Practice Guidelines. Circulation 120: 2271-2306.

21. Holmes DR, Dehmer GJ, Kaul S, Leifer D, O'Gara PT, et al. (2010) ACCF/AHA clopidogrel clinical alert: approaches to the FDA "boxed warning": a report of the American College of Cardiology Foundation Task Force on clinical expert consensus documents and the American Heart Association endorsed by the Society for Cardiovascular Angiography and Interventions and the Society of Thoracic Surgeons. J Am Coll Cardiol 56: 321-341.

22. Simon T, Verstuyft C, Mary-Krause M, Quteineh L, Drouet E, et al. (2009) Genetic determinants of response to clopidogrel and cardiovascular events. N Engl J Med 360: 363-375.

23. Duconge J, Cadilla CL, Renta JY, Silén-Rivera P, Piovanetti P, et al. (2008) Prevalence of CYP2C19 gene polymorphisms in the Puerto Rican population: a preliminary report. P R Health Sci J 27: 357-358.

24. Scott SA, Sangkuhl K, Gardner EE, Stein CM, Hulot JS, et al. (2011) Clinical Pharmacogenetics Implementation Consortium guidelines for cytochrome P450-2C19 (CYP2C19) genotype and clopidogrel therapy. Clin Pharmacol Ther 90: 328-32.

25. Duconge J, Escalera O, Kocherla M, Ruano G (2012) Clinical Implications of Genetic Admixture in Hispanic Puerto Ricans: Impact on the Pharmacogenetics of CYP2C19 and PON1. In: Clinical Applications of Pharmacogenetics.

26. Schroth W, Goetz MP, Hamann U, Fasching PA, Schmidt M, et al. (2009) Association between CYP2D6 polymorphisms and outcomes among women with early stage breast cancer treated with tamoxifen. JAMA 302: 1429-1436.

27. Nakamura K, Goto F, Ray WA, McAllister CB, Jacqz E, et al. (1985) Interethnic differences in genetic polymorphism of debrisoquin and mephenytoin hydroxylation between Japanese and Caucasian populations. Clin Pharmacol Ther 38: 402-408.

28. Horai Y, Nakano M, Ishizaki T, Ishikawa K, Zhou HH, et al. (1989) Metoprolo and mephenytoin oxidation polymorphisms in Far Eastern Oriental subjects: Japanese versus mainland Chinese. Clin Pharmacol Ther 46: 198-207.

29. Yoon YR, Cha IJ, Shon JH, Kim KA, Cha YN, et al. (2000) Relationship of paroxetine disposition to metoprolol metabolic ratio and CYP2D6*10 genotype of Korean subjects. Clin Pharmacol Ther 67: 567-576.

30. Roh HK, Dahl ML, Johansson I, Ingelman-Sundberg M, Cha YN, et al. (1996) Debrisoquine and S-mephenytoin hydroxylation phenotypes and genotypes in a Korean population. Pharmacogenetics 6: 441-447.

31. Gaedigk A, Gotschall RR, Forbes NS, Simon SD, Kearns GL, et al. (1999) Optimization of cytochrome P4502D6 (CYP2D6) phenotype assignment using a genotyping algorithm based on allele frequency data. Pharmacogenetics 9 : $669-682$.

32. Johansson I, Oscarson M, Yue QY, Bertilsson L, Sjoqvist F, et al. (1994) Genetic analysis of the Chinese cytochrome P4502D locus: characterization of variant CYP2D6 genes present in subjects with diminished capacity for debrisoquine hydroxylation. Mol Pharmacol 46: 452-459.

33. Wegman P, Elingarami S, Carstensen J, Stål O, Nordenskjöld B, et al. (2007) Genetic variants of CYP3A5, CYP2D6, SULT1A1, UGT2B15 and tamoxifen response in postmenopausal patients with breast cancer. Breast Cancer Res 9: R7.

34. Wegman P, Vainikka L, Stål O, Nordenskjöld B, Skoog L, et al. (2005) Genotype of metabolic enzymes and the benefit of tamoxifen in postmenopausal breas cancer patients. Breast Cancer Res 7: R284-290. 